\title{
Computational Study on Vibrational Properties of Thyroxine Molecule in Different Charge States
}

\section{S. Dhital, K. Pudasainee, H. P. Lamichhane}

Journal of Nepal Physical Society

Volume 7, Issue 4, December 2021

ISSN: 2392-473X (Print), 2738-9537 (Online)

\section{Editors:}

Dr. Binod Adhikari

Dr. Bhawani Joshi

Dr. Manoj Kumar Yadav

Dr. Krishna Rai

Dr. Rajendra Prasad Adhikari

Mr. Kiran Pudasainee

JNPS, 7 (4), 52-58 (2021)

DOI: http://doi.org/10.3126/jnphyssoc.v7i4.42931
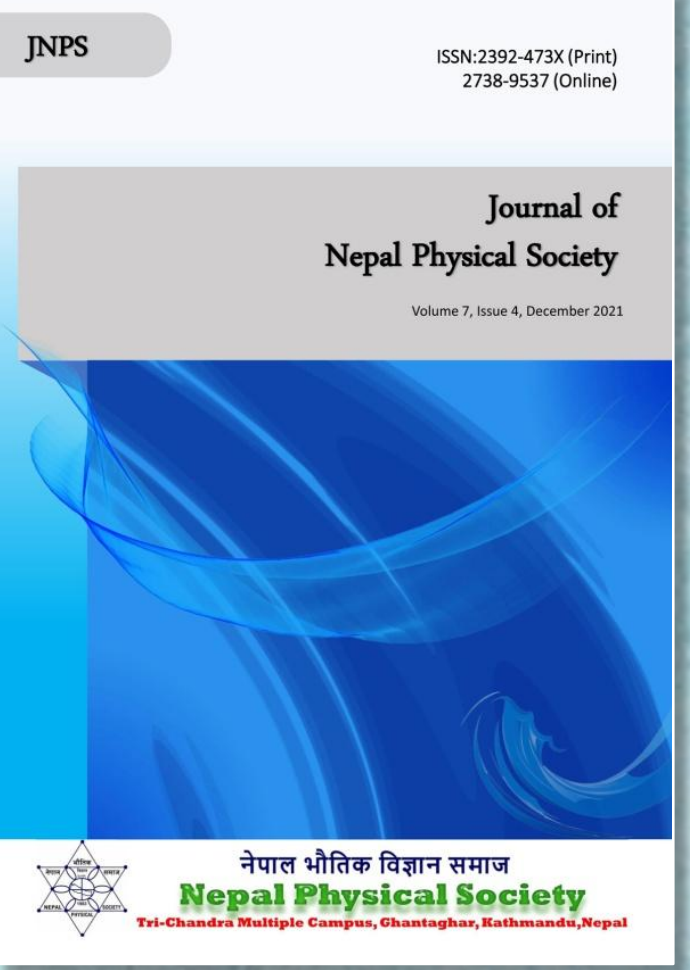

Published by:

Nepal Physical Society

P.O. Box: 2934

Tri-Chandra Campus

Kathmandu, Nepal

Email: nps.editor@gmail.com 


\title{
Computational Study on Vibrational Properties of Thyroxine Molecule in Different Charge States
}

\author{
S. Dhital ${ }^{1}$, K. Pudasainee ${ }^{1}$, H. P. Lamichhane ${ }^{2}$ \\ ${ }^{1}$ Department of Physics, St. Xavier's College, Maitighar, Kathmandu, Nepal \\ ${ }^{2}$ Central Department of Physics, Tribhuvan University, Kirtipur, Kathmandu, Nepal \\ "Corresponding Email: hlamichhane1@gmail.com
}

Received: 9th November, 2021; Revised: 5th December, 2021; Accepted: 25th December, 2021

\begin{abstract}
The vibrational frequencies of thyroxine (T4) molecule are calculated through computational method and major modes of vibration are assigned to corresponding frequencies in this research work. First we took neutral isolated T4 molecule for our study, and then we extend our work to anion state. The shift produced in the frequency and IR intensities for different vibrational modes has been calculated for change in state from neutral to anion. In addition, the difference spectra for these two charge states have also been studied for the T4 molecule by adding the dimethyl sulfoxide (DMSO) solvent. Furthermore, the same calculations are performed for the isolated neutral T4 molecule with $\mathrm{C}^{13}$ labelling. All these calculations are carried out by density functional calculations with the B3LYP hybrid functional applying the SDD effective core potential basis set. The calculated geometrical parameters are in good agreement with the experimental results. Additionally, the calculated frequencies lie within the characteristic region belonging to the respective mode of vibrations.
\end{abstract}

Keywords: Thyroxine, IR intensity, Difference spectra, DMSO.

\section{INTRODUCTION}

Thyroxine is thyroid hormone produced and secreted by the thyroid gland. It is commonly used as a pharmaceutical drug to treat thyroid gland underactivity and metabolic illnesses. It plays significant role in tissue growth and differentiation, protein synthesis and tissue oxygen consumption as well. These importances aroused a lot of curiosities about how it binds with active sites, travels through the body and interacts with hormones and proteins [1]. Hypothyroidism and Hyperthyroidism are two major maladies caused by malfunction of thyroid gland. The rate of cardiac contraction and relaxation is dependent on the concentration of Thyroid hormone in blood. Hyperthyroidism increases the rate of heart beat causing serious cardiac and respiratory problems. And hypothyroidism has diminishing effect on the cardiac contraction and relaxation rate and produces deadly consequences like heart failure [2]. In addition, hormonal imbalance has a significant impact on brain development.
Hormone shortage impacts offspring's response time, language, memory skills, and cerebellar development at various times after birth [3]. Recognizing the relevance of thyroid hormone in tissue protein synthesis and growth and development [4]. We find the necessity for structural elucidation of Thyroxine (T4).

The principle thyroid hormone (thyroxine (T4)) has two isomers namely L-thyroxine and Dthyroxine. Among them L-thyroxine is more active. The molecule of $\mathrm{T} 4$ is composed of two phenyl rings linked with each-other through $\mathrm{C}-\mathrm{C}-$ $\mathrm{C}$ ether linkage. One amino-acid side chain is linked with central phenyl ring $(\alpha)$ and one alcohol functional group connected with outer phenyl ring $(\beta)$. Two iodine atoms are bonded with each ring. The $\mathrm{x}$-ray crystallographic study reveals $\mathrm{C}-\mathrm{C}-\mathrm{C}$ bond angle as $120^{\circ} \pm 3^{\circ}[4]$ at the ether oxygen. In addition, the two rings are oriented nearly perpendicular with the angle between normal to $\alpha$ ring and ether linkage as $+79^{\circ}$ and normal to $\beta$ ring and ether linkage as $-34^{\circ}$ [4]. 
Here we are focused on the vibrational properties i.e. IR spectra of the T4 molecule in two charge states. We have calculated the IR frequency as well as the IR intensities for the different vibrational modes in pure neutral and anion states. Particularly, we have compared the frequencies and intensities for the modes like bending of $\mathrm{NH}_{2}, \quad \mathrm{O}-\mathrm{H}, \quad \mathrm{C}-\mathrm{H}, \quad \mathrm{C}=\mathrm{C}=\mathrm{C}$ and stretching of $\mathrm{C}-\mathrm{H}, \quad \mathrm{C}=\mathrm{C}, \quad \mathrm{C}=\mathrm{O}, \quad \mathrm{CH}_{2}$ etc. Furthermore, we have replaced the $\mathrm{C}^{12}$ atom by $\mathrm{C}^{13}$ atom and then the geometry optimization is done again in neutral state. The corresponding vibrational modes are calculated and again compared for these states.

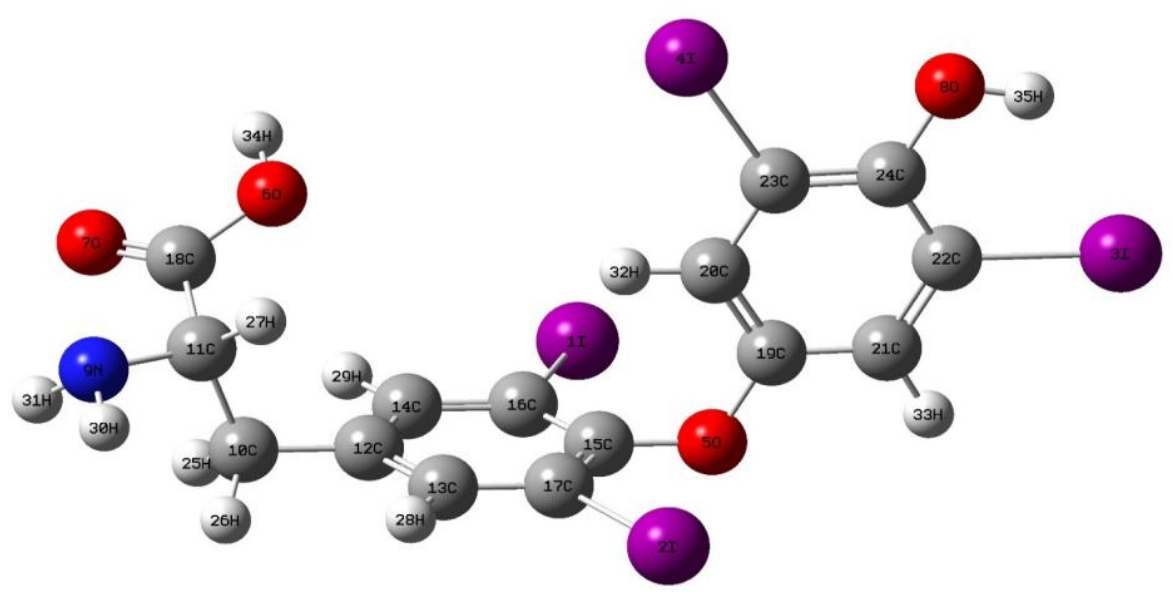

Fig. 1: Structure and numbering scheme of Thyroxine (T4) molecule [5].

\section{COMPUTATIONAL METHOD}

The geometry optimization and vibrational mode analysis were carried out using the density functional theory (DFT) with the GAUSSIAN 09W software package [6]. In addition, for all DFT based calculations, the B3LYP hybrid functional along with the SDD (Stuttgart/Dresden) effective core potential basis set were employed. Due to the existence of iodine atoms that could not be processed at the level of the more regularly used 6$31 \mathrm{G}^{*}$ basis set, this basis set had to be used [7]. The molecular structure model is first constructed within the Gauss View 5 and then optimized to get minimum energy configuration. The computational calculations of the bond length, bond angles and IR absorption spectra of T4 molecule were performed in different charge states (neutral and anion). Similarly, we have studied these properties for neutral and anion states of T4 molecule in gas phase and also in the same states of charge with the addition of solvent dimethyl sulfoxide (DMSO). During the work, first we have assigned the normal modes with corresponding frequencies using the Gauss View software and then tabulated all the vibrational modes and corresponding intensities. Using these calculated vibrational frequencies and intensities we have constructed the IR spectra convolving the stick spectra with the Gaussian function of $4 \mathrm{~cm}^{-1}$ bandwidth.

\section{RESULT AND DISCUSSION}

The calculated vibrational modes and corresponding IR spectra of T4 molecule are presented here. The calculated geometrical parameters like $\mathrm{C}-\mathrm{C}, \mathrm{C}-\mathrm{H}$, and $\mathrm{C}-\mathrm{O}$ bond length and phenyl $\mathrm{C}-\mathrm{C}-\mathrm{C}$ bond angle are measured compared with the experimental result. The data is presented below in table (table 1).

\section{Table 1: Calculated and experimental geometrical parameters for $\mathbf{T} 4$}

\begin{tabular}{llll}
\hline $\begin{array}{l}\text { Geometrical } \\
\text { coordinates }\end{array}$ & \multicolumn{1}{c}{$\begin{array}{c}\text { Calculated } \\
\text { value } \\
\text { (B3LYP/SDD) }\end{array}$} & \multicolumn{1}{c}{$\begin{array}{c}\text { Experimental }^{\mathbf{b}} \\
\text { result }^{\mathrm{a}}\end{array}$} & \\
\cline { 2 - 3 } & Neutral & Anion & \\
Phenyl C-O & 1.40 & 1.42 & 1.41 \\
Phenyl C-C & 1.41 & 1.41 & 1.40 \\
Phenyl C-H & 1.09 & 1.09 & \\
C-I & 2.14 & 2.35 & 2.11 \\
Phenyl C-C- & 119.9 & 120.1 & 119.4 \\
C angle & & & \\
\hline
\end{tabular}

${ }^{a}$ Bond lengths and angles tabulated here in $A$ and degrees respectively.

${ }^{\mathrm{b}}$ Experimental data are taken from the Ref. 8. 
Form the table it is evident that geometrical parameters: bond and angle and bond lengths are in good agreement with the experimental results [8][9]. The vibrational mode assignment is accomplished by visual inspection of vibrations of the molecular groups in Gauss View 5. We are primarily interested in the frequency shifts that occur due to anion environment. Thus we used unscaled frequency to plot the difference spectra. The T4 molecule is formed by 35 atoms and hence it has 99 normal modes of vibrations. Here we have neglected the modes with low infrared intensities taking the most intense vibrations under considerations.

(a) Calculation of vibrational properties of $\mathrm{T4}$ molecule in gas phase in neutral and anion state.

The IR spectra of T4 molecule in neutral and anion state are shown in figure 2 (a), (b), (c) while in the presence of solvent the data are plotted as shown in fig 2 (d), (e), (f).

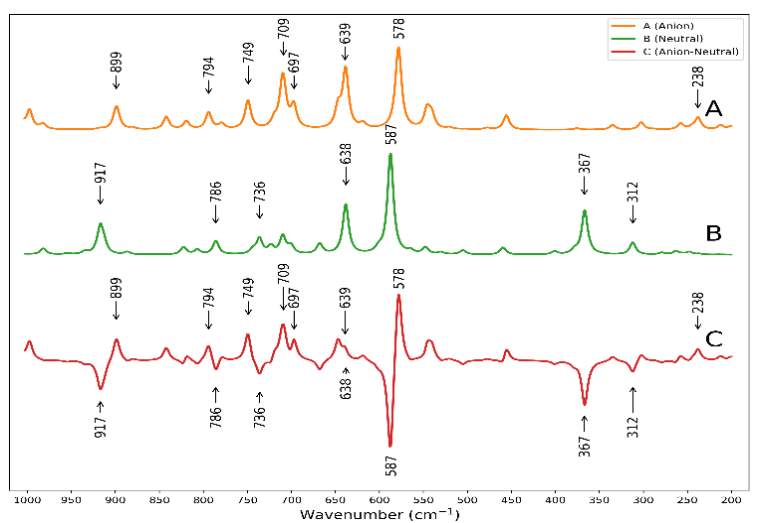

(a)

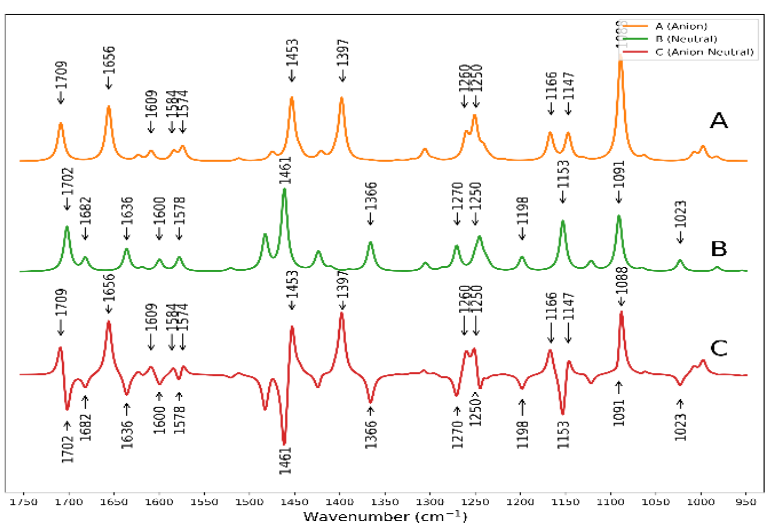

(b)

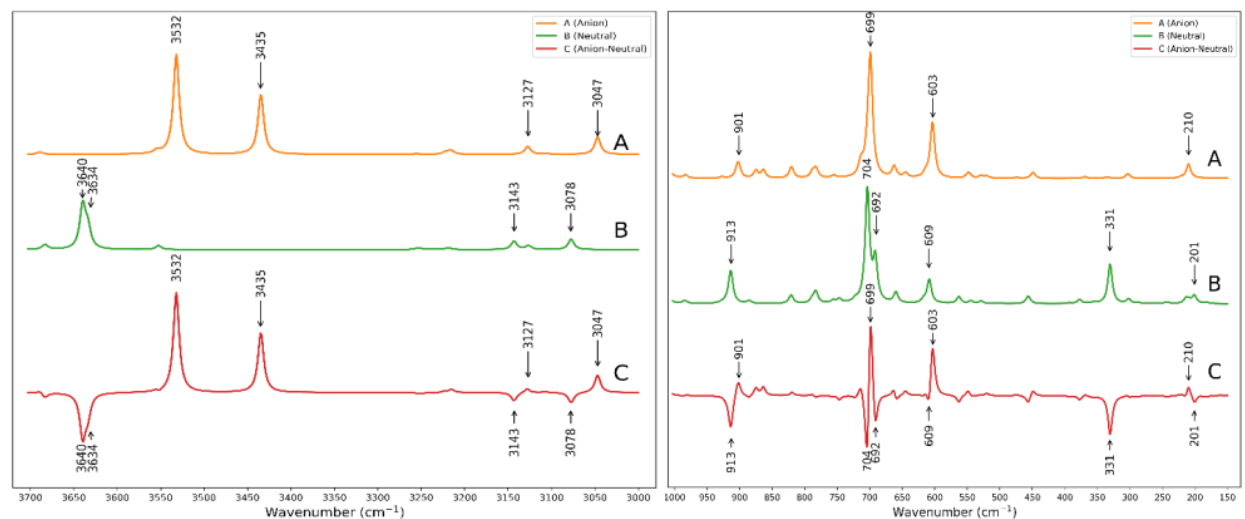

(c)

(d)

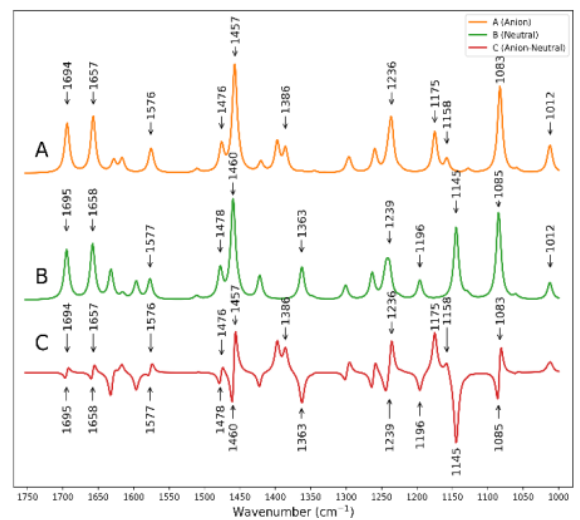

(e)

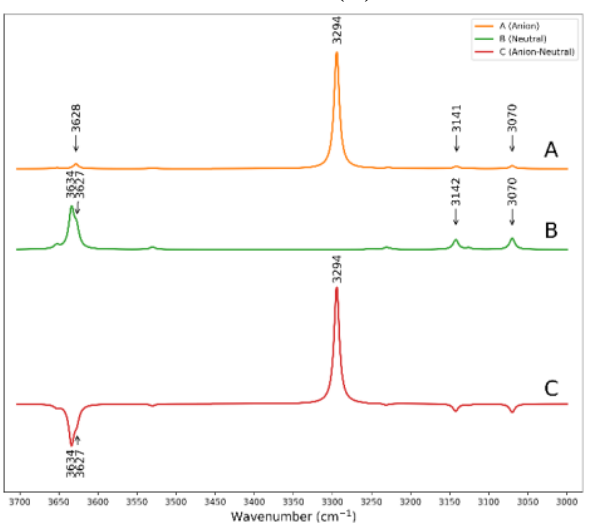

(f)

Fig. 2: Calculated IR spectra of T4 molecule in (a) $1000 \mathrm{~cm}^{-1}-200 \mathrm{~cm}^{-1}$ (b) $1750 \mathrm{~cm}^{-1}-950 \mathrm{~cm}^{-1}$ (c) $3700 \mathrm{~cm}^{-1}-3000 \mathrm{~cm}^{-}$

(d) $1000 \mathrm{~cm}^{-1}-150 \mathrm{~cm}^{-1}$ with solvent (e) $1750 \mathrm{~cm}^{-1}-1000 \mathrm{~cm}^{-1}$ with solvent (e) $3700 \mathrm{~cm}^{-1}-3000 \mathrm{~cm}^{-1}$ with solvent (A-neutral, B-anion, C-difference spectra). 
For the spectrum from $1000 \mathrm{~cm}^{-1}-200 \mathrm{~cm}^{-1}$, the most prominent band in calculated IR spectra of T4 is due to wagging of $\mathrm{NH}_{2}$. This mode occurs at 587 $\mathrm{cm}^{-1}$ in neutral and down-shifts by $9 \mathrm{~cm}^{-1}$ to 578 $\mathrm{cm}^{-1}$ upon anion formation (table 2, fig. 2(a)). The intensity of this mode decreases from $303 \mathrm{~km} / \mathrm{mol}$ to $185 \mathrm{~km} / \mathrm{mol}$ upon anion formation. The same band is observed at $692 \mathrm{~cm}^{-1}$ in neutral and at 699 $\mathrm{cm}^{-1}$ frequency in anion molecule when the solvent DMSO is added to T4. The IR intensity has increased by $385 \mathrm{~km} / \mathrm{mol}$ upon anion environment (table 2, fig 2 (d)). Another peak at $367 \mathrm{~cm}^{-1}$ and at $639 \mathrm{~cm}^{-1}$ in IR spectra of neutral and anion respectively is due to the bending vibration of O8-
H35 (fig. 1). The IR intensity for this mode has decreased by $15 \%$ upon anion formation. But this band is observed at $331 \mathrm{~cm}^{-1}$ in neutral and shifted to $603 \mathrm{~cm}^{-1}$ IR spectrum of anion when the solvent is added in the T4 molecule. Similarly, the O6-H34 (fig. 1) bending vibration is observed at $638 \mathrm{~cm}^{-1}$ in neutral and at $697 \mathrm{~cm}^{-1}$ in anion IR spectrum producing the frequency up-shift of $59 \mathrm{~cm}^{-1}$. The IR intensity, however, has decreased from $150 \mathrm{~km} / \mathrm{mol}$ to $67 \mathrm{~km} / \mathrm{mol}$ upon anion formation (table 2). While when T4 is treated with solvent the O6-H34 (fig. 1) bending vibration is calculated at $609 \mathrm{~cm}^{-1}$ which is shifted to $604 \mathrm{~cm}^{-1}$ upon anion state (fig 2 (d)).

Table 2: The calculated prominent vibrational mode frequencies in $\mathrm{cm}^{-1}$ and intensity in $\mathrm{km} / \mathrm{mol}$ in parenthesis for neutral $\mathrm{T} 4$ and anion $\mathrm{T} 4$.

\begin{tabular}{|c|c|c|c|c|}
\hline \multirow[t]{2}{*}{ Modes } & \multicolumn{2}{|c|}{ T4 in gas phase } & \multicolumn{2}{|c|}{ T4 in DMSO } \\
\hline & Neutral & Anion & Neutral & Anion \\
\hline$\delta_{\text {o.o.p. }}(\mathrm{O} 8-\mathrm{H} 35)$ & 367 (133) & $639(113)$ & $331(206)$ & 603 (179) \\
\hline $\mathrm{NH}_{2}$; wag & $587(303)$ & $578(185)$ & $692(216)$ & $699(601)$ \\
\hline$\delta_{\text {o.o.p. }}(\mathrm{O} 6-\mathrm{H} 34)$ & $638(150)$ & 697 (67) & $609(125)$ & $604(121)$ \\
\hline
\end{tabular}

$\delta$, bending; wag, wagging; o.o.p, out of plane

For the frequency range $1700 \mathrm{~cm}^{-1}-950 \mathrm{~cm}^{-1}$, calculated IR spectra is shown in fig 2 (b) and fig 2 (e). It is easy to notice an intense peak at $1091 \mathrm{~cm}^{-1}$ for neutral molecule (fig 2 (b)). This mode is due to the in plane bending vibration of O6-H34 (fig. 1) bond which is down-shifted to $1088 \mathrm{~cm}^{-1}$ upon anion formation. But the intensity has increased from $221 \mathrm{~km} / \mathrm{mol}$ in neutral to $421 \mathrm{~km} / \mathrm{mol}$ in anion. Furthermore, in the presence of solvent this vibration is observed at $1085 \mathrm{~cm}^{-1}$ and down-shifted to $1083 \mathrm{~cm}^{-1}$ upon anion state. The calculated IR intensity corresponding to this mode is $418 \mathrm{~km} / \mathrm{mol}$ for neutral and $415 \mathrm{~km} / \mathrm{mol}$ for anion state (fig 2 (e), table 3). Similarly, $\mathrm{C}-\mathrm{H}$ bending vibrations are observed at the frequency range from (1461-1153 $\left.\mathrm{cm}^{-1}\right)$ in neutral while at $\left(1453-1167 \mathrm{~cm}^{-1}\right)$ in anion molecule in gas phase. All these modes are listed in table 3. Considering the molecule within the solvent, the $\mathrm{C}-\mathrm{H}$ vibrational modes and corresponding frequencies are listed in table (3) and plotted in the fig. 2 (e). The $\alpha$-ring $\mathrm{C}-\mathrm{H}$ bending vibration is calculated at $1460 \mathrm{~cm}^{-1}$ in neutral while it is observed at $1457 \mathrm{~cm}^{-1}$ in IR spectrum of anion. In addition, the $\beta$-ring $\mathrm{C}-\mathrm{H}$ bending vibration caused a peak at $1196 \mathrm{~cm}^{-1}$ which is down-shifted to $1175 \mathrm{~cm}^{-1}$ upon anion formation in the presence of solvent (fig 2 (e), table 3).
Furthermore, the calculated $\mathrm{NH}_{2}$ scissoring vibration occurs at $1682 \mathrm{~cm}^{-1}$ and down-shifts to $1656 \mathrm{~cm}^{-1}$ upon anion environment. The IR intensity has increased by $211 \mathrm{~km} / \mathrm{mol}$ (table 3 ). This band is calculated at $1658 \mathrm{~cm}^{-1}$ and $1657 \mathrm{~cm}^{-1}$ in neutral and anion states respectively in the presence of solvent (fig. 2 (e)) .The carbonyl $\mathrm{C}=\mathrm{O}$ bond stretching has noticed at $1702 \mathrm{~cm}^{-1}$ in neutral and up-shifts to $1709 \mathrm{~cm}^{-1}$ in anion spectra. The intensity has decreased by $25 \mathrm{~km} / \mathrm{mol}$ as listed in table 3. While the sharp peak at $1695 \mathrm{~cm}^{-1}$ in IR spectrum is assigned to $\mathrm{C}=\mathrm{O}$ stretching mode (fig 2 (e)). Almost no frequency and IR intensity change is noticed for this band upon anion formation in case when solvent is added to T4 molecule (table 3 ).

The calculated O6-H34 9 (fig. 1) stretching mode of vibration of T4 occurs at $3634 \mathrm{~cm}^{-1}$ and downshifts to $3532 \mathrm{~cm}^{-1}$ upon anion formation. The IR intensity is quite high for anion state that is 817 $\mathrm{km} / \mathrm{mol}$ while it is $35 \mathrm{~km} / \mathrm{mol}$ in neutral T4 (fig 2 (c), table 4). Similarly, the O8-H35 (fig. 1) stretching mode of vibrations causes a peak at 3640 $\mathrm{cm}^{-1}$ in IR spectra of neutral T4. This mode of vibration is noticed at $3435 \mathrm{~cm}^{-1}$ for anion T4 with the intensity change of $138 \mathrm{~km} / \mathrm{mol}$ (table 4). Other vibrations are found to be low in intensities therefore they are not included here. In solvent, 
O8-H35 (fig. 1) stretching mode of vibration gives a sharp peak at $3634 \mathrm{~cm}^{-1}$ and is down-shifts to $3294 \mathrm{~cm}^{-1}$ upon anion formation (fig. 2 (f)).
However, the corresponding intensity has increased significantly from just $152 \mathrm{~km} / \mathrm{mol}$ to $1858 \mathrm{~km} / \mathrm{mol}$ (table 4).

Table 3: The calculated prominent vibrational mode frequencies in $\mathrm{cm}^{-1}$ and intensity in $\mathrm{km} / \mathrm{mol}$ in parenthesis for neutral $\mathrm{T4}$ and anion $\mathrm{T} 4$.

\begin{tabular}{lllll}
\hline \multicolumn{1}{c}{ Modes } & \multicolumn{2}{c}{ T4 in gas phase } & \multicolumn{2}{c}{ T4 in DMSO } \\
\cline { 2 - 5 } & \multicolumn{1}{c}{ Neutral } & \multicolumn{1}{c}{ Anion } & Neutral & \multicolumn{1}{c}{ Anion } \\
\hline$\delta_{\text {i.p. }}(\mathrm{O} 6-\mathrm{H} 34)$ & $1091(221)$ & $1088(421)$ & $1085(418)$ & $1083(415)$ \\
$\delta_{\text {i.p. }}(\mathrm{C} 20-\mathrm{H} 32), \delta_{\text {i.p. }}(\mathrm{C} 21-\mathrm{H} 33)$ & $1153(199)$ & $1167(109)$ & $1196(91)$ & $1175(195)$ \\
$\delta_{\text {i.p. }}(\mathrm{C} 20-\mathrm{H} 32), \delta_{\text {i.p. }}(\mathrm{C} 21-\mathrm{H} 33), v(\mathrm{C} 15-\mathrm{O} 5)$ & $1270(99)$ & $1250(164)$ & ------ & ------- \\
$\delta_{\text {i.p. }}(\mathrm{C} 14-\mathrm{H} 29), \delta_{\text {i.p. }}(\mathrm{C} 13-\mathrm{H} 28), v(\mathrm{C} 15-\mathrm{O} 5)$ & $1461(324)$ & $1453(248)$ & $1460(475)$ & $1457(515)$ \\
$\mathrm{NH}_{2} ;$ scis & $1682(51)$ & $1656(216)$ & $1658(264)$ & $1657(270)$ \\
$v(\mathrm{C}=\mathrm{O})$ & $1702(176)$ & $1709(151)$ & $1695(239)$ & $1694(237)$ \\
\hline
\end{tabular}

$\delta$, bending ; $v$, stretching ; scis, scissoring ; i.p., in plane

Table 4: The calculated prominent vibrational mode frequencies in $\mathrm{cm}^{-1}$ and intensity in $\mathrm{km} / \mathrm{mol}$ in parenthesis for neutral $\mathrm{T} 4$ and anion $\mathrm{T} 4$.

\begin{tabular}{|c|c|c|c|c|}
\hline \multirow[t]{2}{*}{ Modes } & \multicolumn{2}{|c|}{ T4 in gas phase } & \multicolumn{2}{|c|}{ T4 in DMSO } \\
\hline & Neutral & Anion & Neutral & Anion \\
\hline$v(\mathrm{O} 6-\mathrm{H} 34)$ & $3634(35)$ & 3532 (877) & $3627(73)$ & $3628(74)$ \\
\hline$v(\mathrm{O} 8-\mathrm{H} 35)$ & $3640(79)$ & $3435(217)$ & $3634(152)$ & $3294 \quad 58)$ \\
\hline
\end{tabular}

$v$, stretching

(a) Calculation of vibrational properties of pure neutral T4 molecule with $\mathrm{C}^{13}$-labelling

The vibrational properties of $\mathrm{T} 4$ molecules are also calculated with the replacement of all $\mathrm{C}^{12}$ atoms by its isotope $\mathrm{C}^{13}$. The IR spectra for T4 are calculated for neutral molecule in its pure state (without solvent). The optimized structure of $\mathrm{T} 4$ with $\mathrm{C}^{13}$ labelling has calculated value of the dihedral angle (C17-C15-C19-C20) equal to $-78.89^{\circ}$.
The IR spectra are plotted by dividing the obtained intensities by two in both cases (pure neutral $\mathrm{T} 4$ and $\mathrm{T} 4$ with $\mathrm{C}^{13}$-labelling). It is evident from the calculations that Similar vibrational modes are seen at approximately equal frequencies with little shift but in case of the vibrations involving the carbon atom the significant frequency shift is noticed.

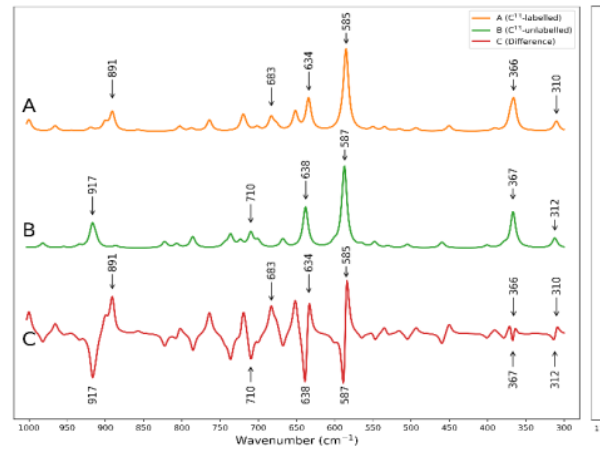

(a

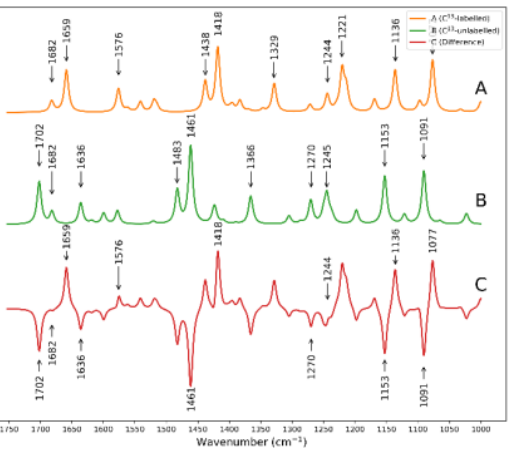

(b)

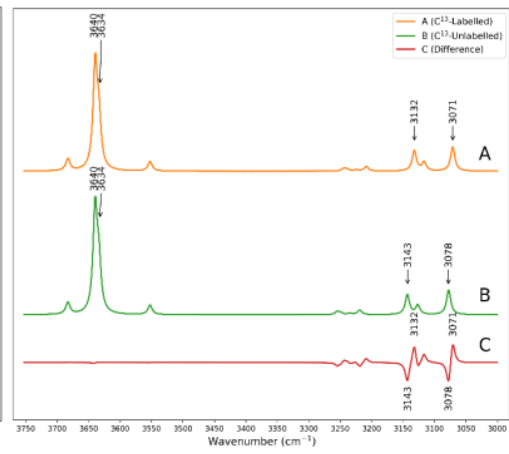

(c)

Fig. 3: Calculated IR spectra of neutral T4 with $C^{13}$ labelling and neutral $\mathrm{T} 4$ with $\mathrm{C}^{12}$ along with difference spectra (a) $1000 \mathrm{~cm}^{-1}-300 \mathrm{~cm}^{-1}$ (b) $1750 \mathrm{~cm}^{-1}-1000 \mathrm{~cm}^{-1}$ (c) $3750 \mathrm{~cm}^{-1}-3000 \mathrm{~cm}^{-1}$ (A-anion, B-Neutral, C-difference spectra) 
The calculated vibrational mode of $\mathrm{NH}_{2}$ wagging is observed at $585 \mathrm{~cm}^{-1}$ when the $\mathrm{C}^{13}$ is labelled while it is found at $587 \mathrm{~cm}^{-1}$ for neutral T4. The intensity here has also been changed by very small value of $2 \mathrm{~km} / \mathrm{mol}$ due to $\mathrm{C}^{13}$ labelling (table 5, fig 3 (a)). Similarly, the bending vibrations of $\mathrm{O} 8-\mathrm{H} 35$ and $\mathrm{O} 6-\mathrm{H} 34$ (fig. 1) are calculated at $366 \mathrm{~cm}^{-1}$ and $634 \mathrm{~cm}^{-1}$ respectively in IR spectrum of $\mathrm{T} 4$ with $\mathrm{C}^{13}$ labelling. But these bands are observed at 367 $\mathrm{cm}^{-1}$ and at $638 \mathrm{~cm}^{-1}$ respectively in IR specturm of neutral T4. The IR intensity has decreased by 29 units in case of former and 31 units in case of later. The calculated mode at $710 \mathrm{~cm}^{-1}$ for $\mathrm{T} 4$ is shifted to $683 \mathrm{~cm}^{-1}$ due to $\mathrm{C}^{13}$ labelling which corresponds to $\mathrm{C}=\mathrm{C}$ bond bending of $\alpha$-ring (table 5, fig 3 (a)).

Table 5: The calculated prominent vibrational mode frequencies in $\mathrm{cm}^{-1}$ and intensity in $\mathrm{km} / \mathrm{mol}$ in parenthesis for $\mathrm{T} 4$ and $\mathrm{T} 4$ with $\mathrm{C}^{13}$-labelling

\begin{tabular}{lll}
\hline \multirow{2}{*}{ Modes } & \multicolumn{2}{c}{ Neutral T4 in gas phase } \\
\cline { 2 - 3 } & \multicolumn{1}{c}{$\mathbf{C}^{\mathbf{1 3}}$-unlabelled } & \multicolumn{1}{c}{$\mathbf{C}^{\mathbf{1 3}}$-labelled } \\
\hline$\delta_{\text {o.o.p. }}(\mathrm{O} 8-\mathrm{H} 35)$ & $367(133)$ & $366(104)$ \\
$\mathrm{NH}_{2} ;$ wag & $587(303)$ & $585(305)$ \\
$\delta_{\text {o.o.p. }}(\mathrm{O} 6-\mathrm{H} 34)$ & $638(150)$ & $634(119)$ \\
$\delta(\mathrm{C}=\mathrm{C}=\mathrm{C})-\alpha$ ring & $710(54)$ & $683(49)$ \\
\hline
\end{tabular}

$\delta$, bending ; wag, wagging

For the frequecies between $1750 \mathrm{~cm}^{-1}$ to $1000 \mathrm{~cm}^{-1}$, the calculated IR spectrum is shown in fig 2(b) and all prominent modes of vibrations are assigned (table 6). The bending vibrations of O6-H34 (fig. 1) bond gives a sharp peak at $1077 \mathrm{~cm}^{-1}$ when $C^{13}$ labelling is done producing the decreament of 14 $\mathrm{cm}^{-1}$ upon $\mathrm{C}^{13}$ labelling. In addition, for this mode, there is not noticeable change in IR intensity i.e. $221 \mathrm{~km} / \mathrm{mol}$ to $216 \mathrm{~km} / \mathrm{mol}$ upon $\mathrm{C}^{13}$ labelling (table 6). Furthermore, the $\mathrm{C}-\mathrm{H}$ bending vibrations provides significant peaks at the frequencies 1153 $\mathrm{cm}^{-1}, 1270 \mathrm{~cm}^{-1}$ and $1461 \mathrm{~cm}^{-1}$ in IR spectrum of neutral T4 molecule while they are observed at $1136 \mathrm{~cm}^{-1}, 1244 \mathrm{~cm}^{-1}$ and $1418 \mathrm{~cm}^{-1}$ in IR spectrum of T4 with $\mathrm{C}^{13}$ labelling. But at $1329 \mathrm{~cm}^{-1}$ for $\mathrm{C}^{13}$ labelled molecule, the $\mathrm{C}=\mathrm{C}$ stretching vibrations provides peak of IR intensity $119 \mathrm{~km} / \mathrm{mol}$. This mode is calculated at $1366 \mathrm{~cm}^{-1}$ for neutral T4 molecule (table 6, fig 3 (b)). The calculated stretching vibration of $\mathrm{C}=\mathrm{O}$ bond gives the peak at $1702 \mathrm{~cm}^{-1}$ and is shifted to 1659 upon $\mathrm{C}^{13}$ labelling. The frequency has decreased by $43 \mathrm{~cm}^{-1}$ for this mode but the IR intensity is lowered by just 2 $\mathrm{km} / \mathrm{mol}$ (table 6 , fig 3 (b)).

Table 6: The calculated prominent vibrational mode frequencies in $\mathrm{cm}^{-1}$ and intensity in $\mathrm{km} / \mathrm{mol}$ in parenthesis for $\mathrm{T} 4$ and $\mathrm{T} 4$ with $\mathrm{C}^{13}$-labelling

\begin{tabular}{lll}
\hline \multicolumn{1}{c}{ Modes } & \multicolumn{2}{c}{ Neutral T4 in gas phase } \\
\cline { 2 - 3 } & \multicolumn{1}{c}{$\mathbf{C}^{\mathbf{1 3}}$-unlabelled } & \multicolumn{1}{c}{$\mathbf{C}^{\mathbf{1}}$-labelled } \\
\hline$\delta_{\text {i.p. }}(\mathrm{O} 6-\mathrm{H} 34)$ & $1091(221)$ & $1077(216)$ \\
$\delta_{\text {i.p. }}(\mathrm{C} 20-\mathrm{H} 32), \delta_{\text {i.p. }}(\mathrm{C} 21-\mathrm{H} 33)$ & $1153(199)$ & $1136(175)$ \\
$\delta_{\text {i.p. }}(\mathrm{C} 20-\mathrm{H} 32), \delta_{\text {i.p. }}(\mathrm{C} 21-\mathrm{H} 33), v(\mathrm{C} 15-\mathrm{O} 5)$ & $1270(99)$ & $1244(72)$ \\
$v(\mathrm{C}=\mathrm{C}) ; \beta-$-ring & $1366(113)$ & $1329(119)$ \\
$\delta_{\text {i.p. }}(\mathrm{C} 14-\mathrm{H} 29), \delta_{\text {i.p. }}(\mathrm{C} 13-\mathrm{H} 28), v(\mathrm{C} 15-\mathrm{O} 5)$ & $1461(324)$ & $1418(267)$ \\
$\mathrm{NH}_{2} ;$ scis & $1682(51)$ & $1682(46)$ \\
$v(\mathrm{C}=\mathrm{O})$ & $1702(176)$ & $1659(174)$ \\
\hline
\end{tabular}

$\delta$, bending; $v$, stretching; scis, scissoring; i.p., in plane 
The calculated stretching mode of vibration of O6-H34 (fig. 1) gives rise to a peak at $3634 \mathrm{~cm}$ ${ }^{1}$ in both the $\mathrm{C}^{13}$-labelled and un-labelled states of T4 (table 7). Also the IR intensities are noticed to be equal in both cases which is equal to $35 \mathrm{~km} / \mathrm{mol}$. Another peak at $3640 \mathrm{~cm}^{-1}$ in both states is due to stretching mode of vibration of
O8-H35 bond (fig. 1). Similar to former one, its intensity is also same i.e. $79 \mathrm{~km} / \mathrm{mol}$ in both states. The $\mathrm{C} 10-\mathrm{H}_{2}$ symmetric stretching gives a peak at $3078 \mathrm{~cm}^{-1}$ for neutral $\mathrm{T} 4$ and shifts to $3071 \mathrm{~cm}^{-1}$ for $\mathrm{C}^{13}$-labelled T4. But the intensities for this mode of vibration is very low (table 7, fig 3 (c)).

\section{Table 7: The calculated prominent vibrational mode frequencies in $\mathrm{cm}^{-1}$ and} intensity in $\mathrm{km} / \mathrm{mol}$ in parenthesis for $\mathrm{T} 4$ and $\mathrm{T} 4$ with $\mathrm{C}^{13}$-labelling

\begin{tabular}{lll}
\hline & Modes & \multicolumn{2}{c}{ Neutral T4 in gas phase } \\
\cline { 2 - 3 } & \multicolumn{1}{c}{$\mathbf{C}^{\mathbf{1 3}}$-unlabelled } & \multicolumn{1}{c}{$\mathbf{C}^{\mathbf{1 3}}$-labelled } \\
\hline$v_{\text {sym }}\left(\mathrm{C} 10-\mathrm{H}_{2}\right)$ & $3078(19)$ & $3071(18)$ \\
$v(\mathrm{O} 6-\mathrm{H} 34)$ & $3634(35)$ & $3634(35)$ \\
$v(\mathrm{O} 8-\mathrm{H} 35)$ & $3640(79)$ & $3640(79)$ \\
\hline
\end{tabular}

$v$, stretching; sym, symmetric

\section{CONCLUSIONS}

We have studied the vibrational modes with their corresponding frequency and the IR intensities of T4 molecule in its neutral and anion states. Furthermore the IR spectrum and intensities of different modes of vibrations for the $\mathrm{T} 4$ molecule when the $\mathrm{C}^{12}$ atom is replaced by its isotope $\mathrm{C}^{13}$ are studied. All the calculated bond angles and bond length are in agreement with the experimentally observed values. In addition, the calculated frequencies of all modes of vibrations are lies in the characteristic region of spectrum. Upon the anion formation, the IR spectrum as well as the IR intensity of normal modes of T4 molecule gets shifted. The shift occurs also when the molecule is in a solvent. This study provides the information regarding the changes in the bond lengths, bond angles and spectroscopic region for normal modes of vibrations for $\mathrm{T} 4$ on its different charge states (neutral, anion).

\section{ACKNOWLEDGEMENTS}

We are grateful to the department of physics, St. Xavier's College, for providing us GAUSSIAN 09W software and computer facilities for our computational work.

\section{REFERENCES}

[1] Hindmarsh, P. Optimization of thyroxin dose in congenital hypothyroidism. Arch Dis Child; 86: 73-75 (2002).

[2] Kendall, E. C. "The isolation in crystalline form of the compound containing iodin, which Occurs in the thyroid: its chemical nature and physiologic activity," Journal of The American Medical Association, 64(25): 2042-2043 (1915).

[3] Zoeller, R. and Rovet, J. "Timing of thyroid hormone action in the developing brain: clinical Observations and experimental findings," Journal of neuroendocrinology; 16(10): 809-818 (2004).

[4] Camerman, N. and Camerman, A. "Threedimensional structure of 1-thyroxin," Proceedings of the National Academy of Sciences; 69(8): 2130-2131 (1972).

[5] Nowak, W. and Wojtczak, A. "Quantum chemical modelling of thyroid hormone analogues," Journal of Molecular Structure: THEOCHEM; 419(1-3): 121-131 (1997).

[6] Frisch, M.; Trucks, G.; Schlegel, H.; Scuseria, G.; Robb, M.; et al. "Gaussian 03, revision c. 02, gaussian, inc., wallingford ct; d) becke, ad (1993) j," Chem. Phys; 98: 5648-5652 (2004).

[7] Alvarez, R. M.; Farías, R. N. and Hildebrandt, P. "Comparative vibrational analysis of thyro-nine hormones using infrared and raman spectroscopy and density functional theory calculations," Journal of Raman Spectroscopy; 35(11): 947-955 (2004).

[8] Harington, C. R. "Chemistry of thyroxine: isolation of thyroxine from the thyroid gland," Biochemical Journal; 20(2): 293-299 (1926).

[9] Ferraro, J. R., Introductory raman spectroscopy. Elsevier, 2003.

[10] Levine, I. N. Quantum chemistry. Prentice-Hall of India, 2010.

[11] Hehre, W. J., A guide to molecular mechanics and quantum chemical calculations; 2: (2003).

[12] Sholl, D. and Steckel, J. A. Density functional theory: a practical introduction. John Wiley \& Sons (2011). 